\title{
Description of a new species Topomyia (Suaymyia) lehcharlesi (Diptera: Culicidae) from Sarawak, Malaysia
}

\author{
Ichiro MiYAGI ${ }^{1,2)}$ and Takako Toma ${ }^{2)}$ \\ 1) Laboratory of Mosquito Systematics of Southeast Asia and Pacific, c/o Ocean Health \\ Corporation, 4-21-11, Iso, Urasoe, Okinawa, 901-2132 Japan \\ 2) Laboratory of Medical Zoology, School of Health Science, Faculty of Medicine, \\ University of the Ryukyus, Nishihara, Okinawa, 903-0215 Japan
}

(Received: 21 March 2008; Accepted: 19 May 2008)

\begin{abstract}
Topomyia (Suaymyia) lehcharlesi n. sp. is described based on male, female, pupal and larval specimens collected from Sarawak, Malaysia. This species is very similar to To. (Sua.) argenteoventralis but can be distinguished by the claspette and dorsomedian lobe of the male genitalia and 5-6 unpaired large spine-like siphonal setae (1a) on the larva.
\end{abstract}

Key words: Topomyia lehcharlesi, mosquito, Culicidae, Sarawak, Malaysia

In 2006, adult male, adult female, pupae and larvae of Topomyia (Suaymyia) argenteoventralis Leicester, 1908 were redescribed based on specimens collected from Gombak, Peninsular Malaysia (Miyagi et al., 2006). The larvae of this species are characteristic and can be distinguished easily from any other species of the subgenus by a siphon with 6-8 unpaired strong spine-like setae. A new species, Topomyia (Suaymyia) nepenthicola Miyagi and Toma (Miyagi and Toma, 2007) was found in Nepenthes pitcher plants from Bario Highland (approximately 1,000 m elevation), Sarawak, Malaysia.

We also collected several interesting larvae from Padawan, Kuching, Sarawak, Malaysia in 2006. The larvae were somewhat similar to To. argenteoventralis and To. nepenthicola with very long spine-like siphonal setae and large maxillae, but the genitalia of the males from the larvae were different. We, therefore, concluded this is a new species and describe it in this paper. This study was carried out with cooperation from the Sarawak Museum of Natural History, Kuching, Malaysia. Permission was obtained to conduct research on biological resources/collected samples of biological resources for research purposes and permit No. NPW.907.4.2-98 from the Director of Forest, Sarawak.

The terminology used for the adults and immature stages mainly follows Harbach and Knight (1980, 1981), but partially follows Belkin (1962) and Harbach and Peyton (1993).

\section{Topomyia (Suaymyia) lehcharlesi \\ Miyagi and Toma, n. sp. (Figs. 1-3; Tables 1, 2)}

Male.

Head: Black in dorsal aspect; vertex closely covered with broad flat dark scales, with somewhat purple reflections; apical part of vertex with a diamond-shaped silver scale patch; a line of yellow scales along ocular suture; erect scales and narrow decumbent scales absent on occiput; postgena covered with a small silver scale patch. Clypeus small, dark brown. Maxillary palpus black, short, about 0.05 of proboscis, covered with dark scales. Proboscis black, slender, $2.15 \mathrm{~mm}$, longer than antenna; slightly swollen at the distal end and covered with a ventral line of white scale. Pedicel brown closely covered with fine grayish scales. 


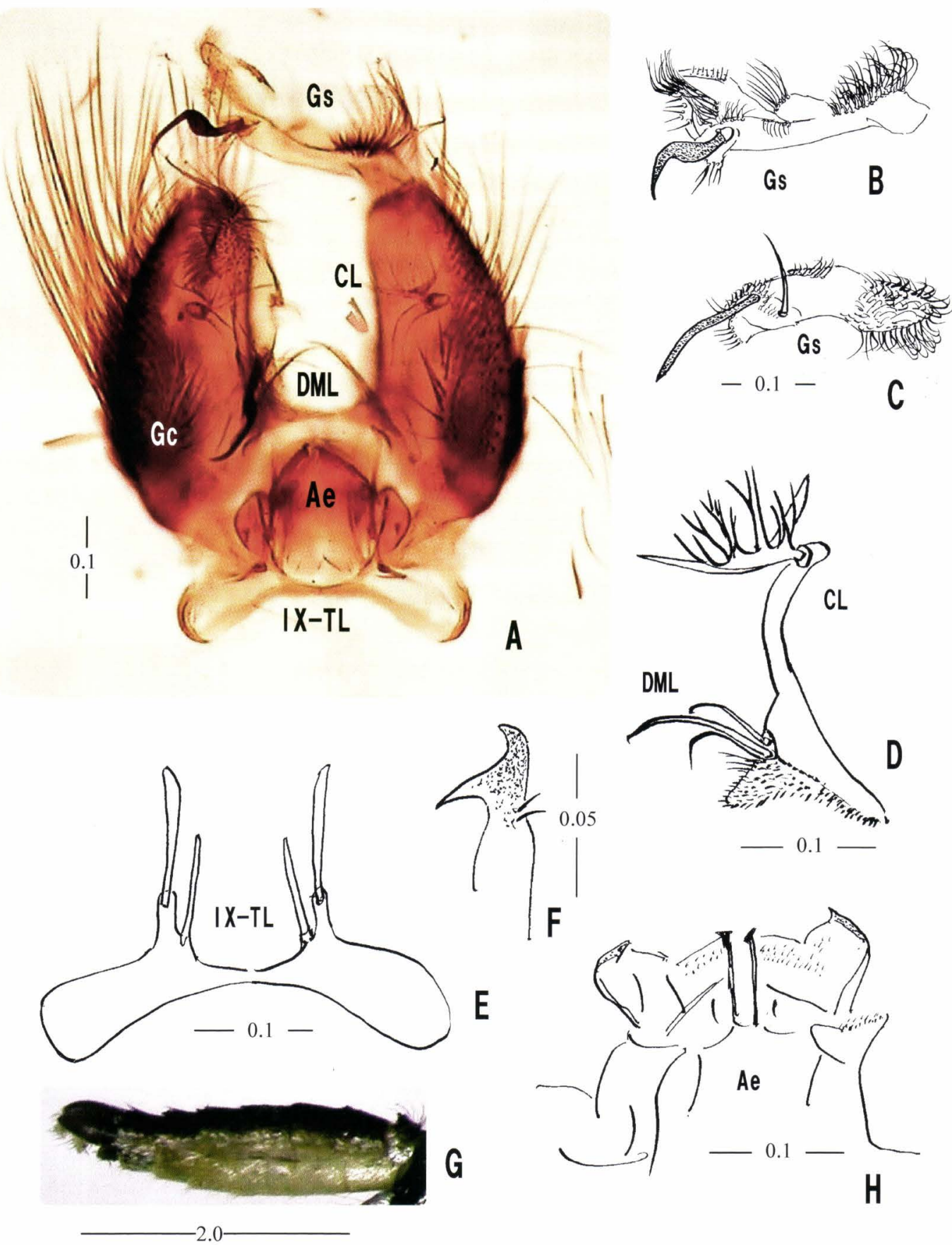

Fig. 1. Male genital organs $(\mathrm{A}-\mathrm{F}, \mathrm{H})$ and abdomen $(\mathrm{G})$ of Topomyia (Suaymyia) lehcharlesi $\mathrm{n}$. sp.

A, Gonocoxite (Gc), dorsal view; B, C, apical part of gonostylus (Gs), different view; D, dorsomesal lobe (DML) and claspette with caribou antler-like terminal appendage (CL); E, tergum IX lobe (IX-TL); F, paramere (Par), lateral view; G, male abdomen, lateral view; $H$, aedegus (Ae). Scales in mm.

Thorax. Scutum densely covered with velvety black scales and with a median silvery line from anterior promontory to prescutellar area; the line consisting of double rows of overlapping flat silvery scales; many antealars and supraalars present. Thoracic pleura densely 
covered with silvery reflect spatulate scales on upper and lower postpronotal, antepronotal, upper proepisternal, postspiracular, subspiracular, prealar, upper and lower mesokatepisternal, upper mesepimeral and metepisternal areas. Conspicuous black setae absent on the pleuron, except about 10 antepronotals, 2 prealars and 4 upper mesokatepisternals. Scutellum with flat silvery scales and 1 or 2 well developed setae on median lobe, and 3 or 4 setae on each lateral lobe and with black spatulate scales.

Wing. Length $3.67 \mathrm{~mm}$ : Cell $\mathrm{R}_{2}$ about 3.0 of stem $\mathrm{R}_{2+3}$; alula with $6-7$ fine scales on margin distally; upper calypter without setae. Haltere: Scabellum pale, pedicel and capitellum with dark scales.

Legs. Coxae and trochanters yellow, with silvery-white scales, trochanters with some dark scales dorsally at apex; femora, tibiae and tarsi dark scaled dorsally, yellow scaled ventrally. Forefemur $2.65 \mathrm{~mm}$. Forefemur as long as mid- and hindfemora; first tarsal segments of all legs (Ta- $\mathrm{I}_{1}-\mathrm{Ta}^{\left.-\mathrm{III}_{1}\right)}$ as long as each tibia (Ti-I-Ti-III). Unguis of foreleg larger than those of mid- and hindlegs. All ungues equal in size, without a lateral tooth.

Abdomen. Length $2.55 \mathrm{~mm}$. Terga darkscaled without white dorsal patch on all segments (Fig. 1G). All sterna with white spatulate scales.

Genitalia (Fig. 1A-F, H). Lobes of tergum IX (Fig. 1E) widely separated by narrow bridge, each lobe attenuated apically, terminating in single stout large blade-like seta, the seta longer than the stem of the lobe, and one seta closely spaced on inner basal margin of each lobe. Gonocoxite about 2.9 times breadth at middle. Dorsomedian lobe (Fig. 1D) with one long stout flattened spine and with 2 well developed setae apically curved. Claspette (Fig. 1D) well developed with a peculiar caribou antler-like (multi-branched) terminal appendage. Gonostylus (Fig. 1B, C) complicated with many curved setae dorsoapically and dorsobasally. Large gonostylar claw curved apically and well-developed setae behind the claw. Paramere (Fig. 1F) or paraproct slender curved apically. Aedegus as in Fig. 1H.

\section{Female.}

Wing. $3.87 \mathrm{~mm}$. Proboscis, $2.30 \mathrm{~mm}$. Forefemur $2.50 \mathrm{~mm}$. Abdomen $2.90 \mathrm{~mm}$. Resembles male, except abdominal spots: terga cov- ered with dark purple-brown scales, a large patch of white scales on the 1st and 2nd segments, patch of white scales on the 4 th to the 6 th segments.

Pupa (Fig. 2A-D, Table 1).

Abdomen. 3.45-4.00 $\mathrm{mm}$ length (from segments I to VIII). Trumpet $0.40-0.45 \mathrm{~mm}$, index 3.40-4.50. Paddle $0.60-0.66 \mathrm{~mm}$, index $2.00-$ 2.24. Chaetotaxy as figured and given in Table 1. Metanotum and cephalothorax (Fig. 2A, C): Trumpet (Fig. 2D) yellow-brown in color, with fine sculpturing, not strongly broadened widely towards pinna. Seta 1-CT long, conspicuous, double. Abdominal seta 1-I (Fig. 2B) fanlike with 6-15 main branches, $3-$ II, III usually single, well developed. Seta 5-IV-VI single, large; seta 9-VII, VIII large, barbed, 8-30 branched. Paddle long, ending in a point, uniformly and lightly pigmented with a midrib and with minute spicules along apical margin. Male and female genital lobes extending to about 0.76 and 0.37 of paddle respectively.

Fourth-instar Larva (Fig. 3, Table 2).

Head (Fig. 3C). Length $0.9-1.0 \mathrm{~mm}$, width $1.0-1.2 \mathrm{~mm}$. Siphon (Fig. 1G) $0.8-1.0 \mathrm{~mm}$. Chaetotaxy in Table 2 and Figure 3. Mental plate (Fig. 3D) with median large tooth and 8 small teeth on either side. Mouth parts modified for predation. Mouth brushes stout pectinate. Mandible (Fig. 3E) black, with a large apical tooth (DT) and 3, 4 ventral teeth; mandibular rake blade 1 (MRB1) large, a row of several mandibular brush $(\mathrm{MnB})$ with strong seta $2 \mathrm{a}-\mathrm{Mn}(2 \mathrm{a})$. Maxilla (Fig. 3F) large, about $0.38 \mathrm{~mm}$; maxillary bundle $(\mathrm{MxBn})$ well developed, shorter than length of maxillary body (MxBo). $\mathrm{MxBn} / \mathrm{MxBo}$ index 0.52 ; a row of several well developed laciniarastrum (LR); apical teeth (AT) small process, about $1 / 2$ of $\mathrm{MxBn}$, with incised blade tipped; seta 3 on MxBo well developed, single, situated at basal 0.71 of maxillary body, setae 1 and 2 small. Antenna length about $0.32 \mathrm{~mm}$. Seta 1-A weak, single, arising 0.75 from base, extending over tip of antenna. Seta 1-C stout, simple; setae 6, 11 comparatively well developed single. Abdomen (Fig. 3 B, G). Setae pigmented. Seta 5 stellate with aciculate branches present on segments III-VI. Seta $6-\mathrm{I}-\mathrm{V}$ well developed, 1-12 branched with aciculate. Seta 7-I, II 3-5 branched with aciculate. Setae $6-\mathrm{VI}$ and $3-\mathrm{VII}$ single stout with aciculate. Comb scales $15-17$ 


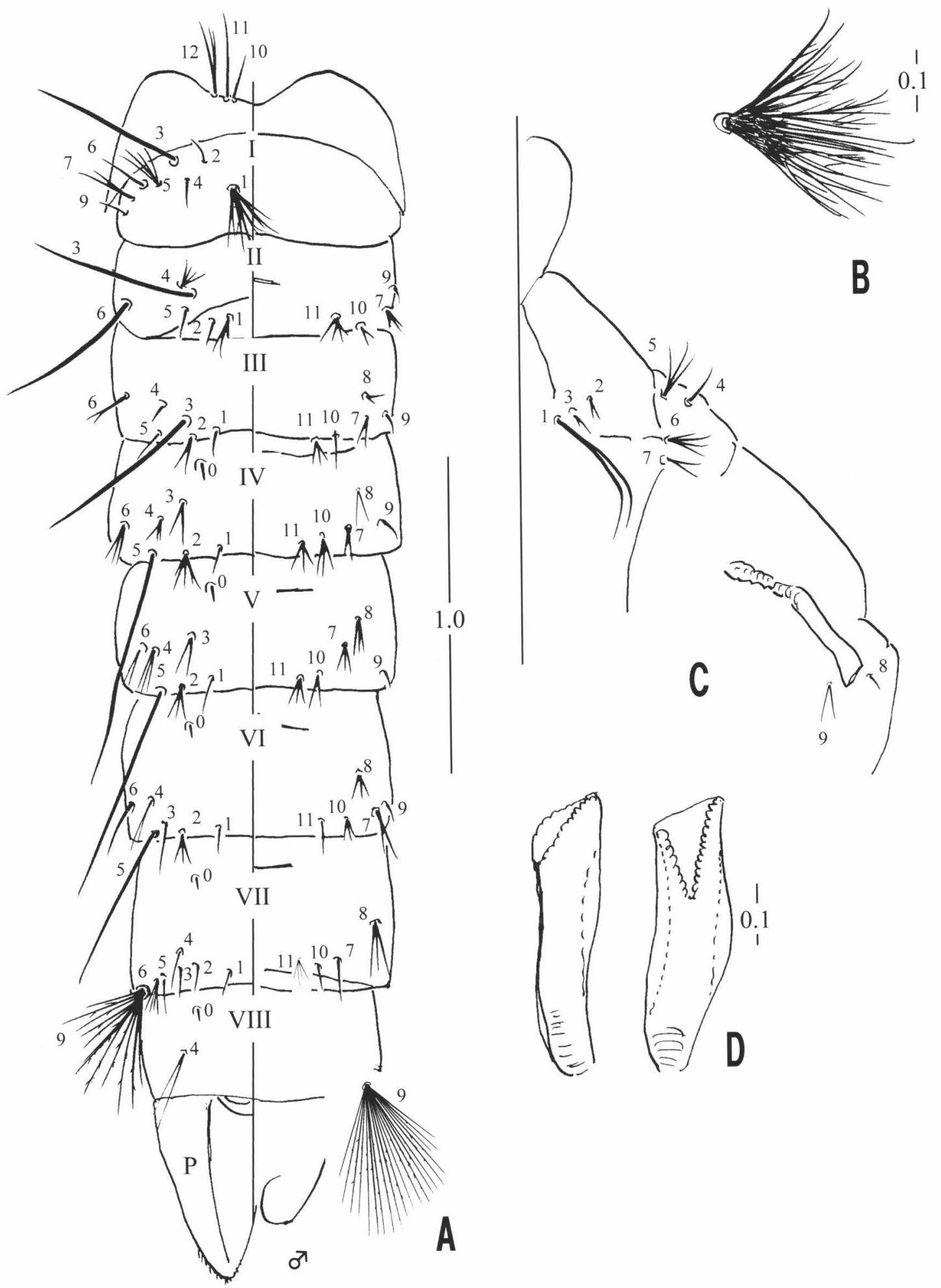

Fig. 2. Pupa of Topomyia (Suaymyia) lehcharlesi n. sp. A, metanotum and abdomen of male; B, Seta 1-I; C, cephalothorax; D, trumpet, lateral and ventral views. Scales in $\mathrm{mm}$. 
Table 1. Chaetotaxy of the pupae of Topomyia (Suaymyia) lehcharlesi n. sp.

\begin{tabular}{|c|c|c|c|c|c|c|c|c|c|}
\hline \multirow{2}{*}{$\begin{array}{c}\text { Seta } \\
\text { no. }\end{array}$} & \multirow{2}{*}{$\begin{array}{l}\text { Cephalo- } \\
\text { thorax }\end{array}$} & \multicolumn{8}{|c|}{ Abdominal segments } \\
\hline & & I & II & III & IV & $\mathrm{V}$ & VI & VII & VIII \\
\hline 0 & - & - & 0 & 0 & 1 & 1 & 1 & 1 & 1 \\
\hline 1 & 2 & $6-15^{*}$ & $3-6$ & 1 & 1 & 1 & 1 & 1 & - \\
\hline 2 & $2-4$ & 1 & 1 & $1-5$ & $3-5$ & $2-5$ & $3-5$ & 1,2 & - \\
\hline 3 & $1-4$ & 1 & $1(1,2)$ & 1 & $2-5$ & $1-3$ & 1,2 & $1-3$ & - \\
\hline 4 & $1-4$ & 1,2 & $3-7$ & $1-5$ & $1-5$ & $2-6$ & $1-3$ & 1,2 & 1,2 \\
\hline 5 & $3-5$ & $2-10$ & 1,2 & 1,2 & 1 & 1 & 1 & $1-3$ & - \\
\hline 6 & $1-4$ & 1 & 1 & $1-4$ & $2-6$ & $1-3$ & 1,2 & $2-4$ & - \\
\hline 7 & $1-4$ & 2,3 & $1-3$ & $2-6$ & $1-4$ & $4-7$ & 1,2 & 1,2 & - \\
\hline 8 & 1,2 & - & - & $1-4$ & $2-4$ & $2-4$ & $2-7$ & $3-7$ & - \\
\hline 9 & 2,3 & $1(1,2)$ & 1 & 1 & 1 & 1 & 1 & $8-26^{* *}$ & $20-30^{* *}$ \\
\hline 10 & 1,2 & - & $2-4$ & $1-5$ & $3-5$ & $2-5$ & $3-5$ & $1-4$ & - \\
\hline 11 & 1 & - & $2-5$ & $2-5$ & $2-4$ & $2-4$ & $1-3$ & $3-6$ & - \\
\hline 12 & $1-4$ & - & - & - & - & - & - & - & - \\
\hline
\end{tabular}

* Fanlike setae with 6-15 main branches.

** Aciculated.

Obsolate and missing setae are indicated with a hyphen (-).

Specimens examined: 6 pupal exuviae from Penrissen Highlands, Padawan, Kuching, Sarawak.

in a row; individual scales (Fig. $3 \mathrm{H}$ ) usually pointed and with fine fringes towards base. Siphon (Fig. 3G). Usually long, variable length, broad at base, tapering, lightly pigmented. Siphonal index about 7.7. Many small pecten teeth placed irregularly. Ventral setae (1a) of siphon 5-6, unpaired, well developed into strong, simple setae, but the apical and basal two small, 1-3 branched. Dorsal seta (2a) 2 pairs, the apical one fine with $2-4$ branches, the basal one well developed, single. Saddle incomplete, with fine spines on posterior margin. Seta 1-X 3, 4 branched with aciculate, 2-X 917 branched, $3-\mathrm{X}$ single, 4-X 10-17 branched. Gill elongate, tapering.

\section{Specimens examined}

Type material. Holotype male (0609231) on a pin with L (larval) and P (pupal) exuviae mounted on a slide (288) and genitalia on a slide (G25), collected as larva from leaf axils of Donax sp. of Penrissen Highlands, Padawan, Sarawak, Malaysia, and reared to adults in the laboratory.

Paratypes. 10 (060923-1) with L and $\mathrm{P}$ (470), (G80) on slides; $10^{\top}$ (060923-1) with P (512), (G62); 107 (060923-1) with L, P (515); 10 (060923-1) with L, P (466); 10 (060904-1) with L, P (290), (G33); 1우 (060904-1) with L, P (176); 3 whole larvae
(060904-1, 060923-1); 2 larval exuviae on slides (060923-1, 060904-1), same data as the holotype. All specimens were collected by I. Miyagi and T. Toma. Holotype will be deposited in the U.S. National Museum and some of the specimens will be deposited in the Sarawak Museum, Kuching, Malaysia and U.S. National Museum, Washington DC, U.S. A. after our taxonomic studies on the genus Topomyia is completed.

Etymology. It is our honor to dedicate this new species To. lehcharlesi to Dr. Moi Ung Charles Leh, Charles, Curator of Natural History Department, Sarawak Museum, Kuching, Sarawak, Malaysia, for his support and encouragement during field research on mosquitoes in Sarawak.

Taxonomic Discussion. Topomyia lehcharlesi n. sp. is very similar in external appearances to Topomyia (Suaymyia) argenteoventralis Leicester, 1908 collected from Malaysia and Indonesia (Edwards, 1922; Miyagi et al., 2006) and Topomyia (Suaymyia) nepenthicola Miyagi and Toma, 2007 from Bario, Sarawak, Malaysia (Holotype in the US National Museum). These three 

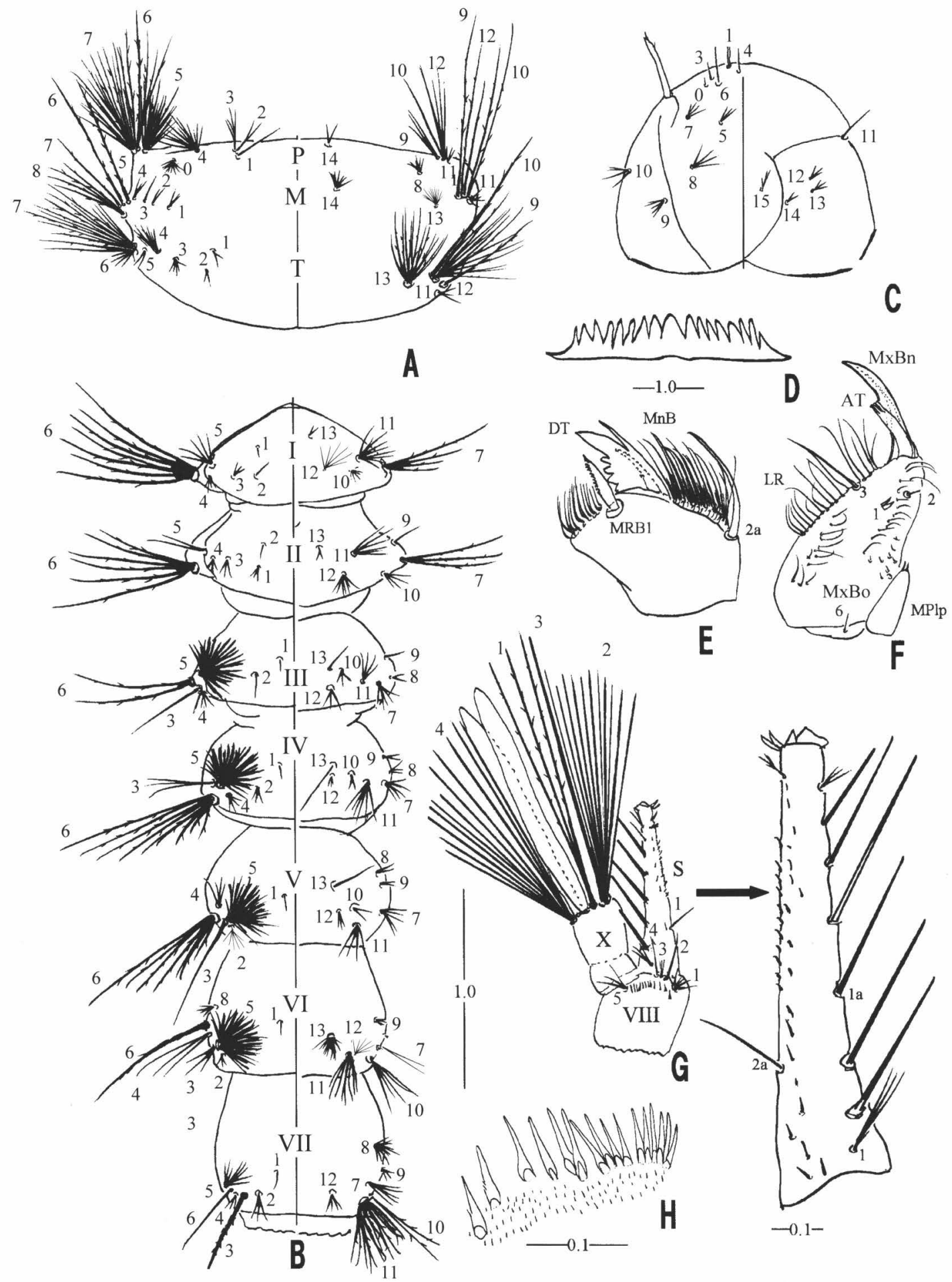

Fig. 3. Larva of Topomyia (Suaymyia) lehcharlesi n. sp. A, thorax; B, abdominal segments of I-VII; C, head; D, dorsomentum; E, mandible; F, maxilla; G, segments VIII, X and siphon; H, comb scales. Scales in $\mathrm{mm}$. 
Table 2. Chaetotaxy of the larvae of Topomyia (Suaymyia) lehcharlesi n. sp.

\begin{tabular}{|c|c|c|c|c|c|c|c|c|c|c|c|c|}
\hline \multirow{2}{*}{$\begin{array}{c}\text { Seta } \\
\text { no. }\end{array}$} & \multirow{2}{*}{ Head } & \multicolumn{3}{|c|}{ Thorax } & \multicolumn{8}{|c|}{ Abdominal segments } \\
\hline & & $\mathrm{P}$ & M & $\mathrm{T}$ & I & II & III & IV & $\mathrm{V}$ & VI & VII & VIII \\
\hline 0 & 1 & $9-15$ & - & - & - & - & - & - & - & - & - & - \\
\hline 1 & 1 & 1,2 & 3,4 & $1-7$ & 1 & $1-3$ & 1 & 1 & 1 & 1 & 1 & $6-15$ \\
\hline 2 & - & $1-5$ & $2-4$ & $2-5$ & 1 & 1,2 & 1,2 & $3-5$ & $6-8$ & $2-9$ & $3-5$ & 1 \\
\hline 3 & 1 & $2-5$ & 1 & $5-13$ & $3-8$ & $3-9$ & 1,2 & 2,3 & $1-3$ & $1-4$ & $1^{*}$ & $1-6$ \\
\hline 4 & 1 & $13-23^{*}$ & 3,4 & $2-8$ & $3-6$ & $4-7$ & $5-7$ & $4-7$ & $4-7$ & 2,3 & $3-6$ & $1^{*}$ \\
\hline 5 & $2-4$ & $16-22^{*}$ & $1^{*}$ & $1-5$ & $5-14$ & $2-4$ & $22-43^{* *}$ & $25-34^{* *}$ & $38-52^{* *}$ & $35-48^{* *}$ & $8-12$ & 2,3 \\
\hline 6 & 1 & $4,5^{*}$ & $1,2^{*}$ & 4,5 & 5-8* & 6-9* & $1-3^{*}$ & $8-12^{*}$ & $7-10^{*}$ & $1^{*}$ & 1 & - \\
\hline 7 & $4-8$ & $16-21 *$ & $1^{*}$ & $13-18^{*}$ & $3-5 *$ & $2-7^{*}$ & $5-11$ & 5-11 & 5,6 & 1,2 & 5-10 & $1-\mathrm{X}=3,4^{*}$ \\
\hline 8 & $4-6$ & $5-9$ & $4-7^{*}$ & - & - & - & $2-7$ & $3-5$ & $2-5$ & $3-14$ & $10-14$ & \\
\hline 9 & $5-8$ & $2-4^{*}$ & $1,2^{*}$ & $14-19 *$ & - & 1 & $1-4$ & $2-4$ & $2-5$ & $2-9$ & $2-14$ & $2-X=9-17$ \\
\hline 10 & $3-6$ & $1^{*}$ & $1,2^{*}$ & $1^{*}$ & $2-10$ & 4-9 & $3-6$ & $2-5$ & $2-7$ & $6-8^{*}$ & $2-5^{*}$ & \\
\hline 11 & $1-3$ & $2-4$ & $2-4$ & $1-3$ & 8-12 & $5-12$ & $4-7$ & $4-8$ & $4-8$ & $4-8$ & $10,11^{*}$ & $3-X=1$ \\
\hline 12 & $3-6$ & $3-5^{*}$ & $1^{*}$ & $1^{*}$ & $5-7$ & $6-10$ & $2-6$ & $3-5$ & $3-7$ & $5-7$ & $4-7$ & \\
\hline 13 & $3-7$ & - & $12-19$ & $13-21^{*}$ & 2 & 1,2 & 1 & 1,2 & 1,2 & $11-22$ & - & $4-X=10-17$ \\
\hline 14 & $2-5$ & $2-4$ & $6-8$ & - & - & - & - & - & - & - & - & - \\
\hline 15 & $1-8$ & - & - & - & - & - & - & - & - & - & - & - \\
\hline
\end{tabular}

* Aciculated. ** Stellate.

Obsolate and missing setae are indicated with a hyphen (-).

Specimens examined: 4 fourth-stage larvae and larval exuviae from Penrissen Highlands, Padawan, Kuching, Sarawak.

species have the following common characters in the male genitalia and the siphon of the larva. The claspette is well developed with characteristic terminal appendages and several unpaired strong spin-like setae in the siphon and modification of the maxilla for predacious feeding. The larvae of To. lehcharlesi and To. argenteoventralis are found in the leaf axils of many plants but larvae of To. nepenthicola are found exclusively in Nepenthes stenophylla. We believe this new species, To. lehcharlesi, is an ancient derivative of To. argenteoventralis found in Indonesia ( $\mathrm{Su}$ matra) and Malaysia (Selangor, Peninsular Malaysia). The pupae and the adult females of the three species are difficult to distinguish from each other but the larvae and adult males are easily distinguished by the following keys:

\section{Larva}

1. Siphon with 11-14 unpaired strong spine-like ventral setae (1a) apparently aciculated. Maxillary bundle $(\mathrm{MxBn})$ longer than the length of maxillary body (MxBo). Seta $1-\mathrm{X} 4$ branched, 3-X 2 branched …................. To. nepenthicola

- Siphon with 5-8 unpaired spine-like setae not apparently aciculated. $\mathrm{MxBn}$ shorter than MxBo. Setae $1-X \quad 1-3$ branched, $3-\mathrm{X}$ single. $\cdots \cdots \cdots \cdots \cdots \cdots \cdots \cdots \cdots \cdots \cdots \cdots \cdots \cdots \cdots$

2. Seta 6 -VI single and simple. Less than 7 (5-7) comb scales in an irregular row. ......................... To. argenteoventralis

- Seta 6-VI single, stout with fine aciculation. Usually 16 comb scales in a row ....................... To. lehcharlesi n.

Adult male

1. Terga dark-scaled, slightly marked lateral white bands on all segments, the bands broad in segments I, IV and V. Genitalia, stem of claspette short with a long gradually twisted prominent terminal seta. Gonostylus with apical lobe rectangular, about 13 leaflets in a row. To. nepenthicola

- Terga without lateral white bands on all segments. Stem of claspette long with terminal appendage. Apical lobe with many fine setae..............................

2. Claspette with a flower-like terminal appendage $\cdots \cdots \cdots \cdots \cdots \cdots$......... argenteoventralis

- Claspette with a caribou antler-like terminal appendage $\cdots \cdots . .$. To. lehcharlesi n. 
sp.

Biological notes. The larvae of To. lehcharlesi are predacious and found singly in the leaf axils of Donax sp. The female appears to be autogenous, because she never feeds when reared in a cage.

Distribution. Known only from the Padawan outskirts of Kuching, Sarawak, Malaysia.

\section{ACKNOWLEDGEMENTS}

We thank Dr. Moi Ung Charles Leh, Mr. Yakup Mawi, Mr. Affinidi Muhidden and Mr. Mahmud Muhidden, Natural History Museum Sarawak, Kuching, Malaysia for their kind cooperation in the field study. Special thanks are due to Dr. Takao Okazawa of Kanazawa University for his kind support in field investigations and Mr. Keisyo Miyagi, President of the Ocean Health Corporation, Urasoe, Okinawa for his support. We also thank Dr. Hoi Sen Yong, Senior Fellow, Academy of Sciences Malaysia and Professor Emeritus, University of Malaya for critically reviewing the manuscript.

\section{REFERENCES}

Belkin, J. N. 1962. The Mosquitoes of the South Pacific (Diptera: Culicidae). Vols. I and II. 608 and 412 pp., University of California Press, Barkeley and Los Angeles.

Edwards, F. W. 1922. A synopsis of adult Oriental culicine (including megarhine and sabethine) mosquitoes. Part II. Indian J. Med. Res., 10: 430-475.

Harbach, R. E. and Knight, K. L. 1980. Taxonomists' Glossary of Mosquito Anatomy. 415 pp., Plexus Publishing Inc., Marlton.

Harbach, R. E. and Knight, K. L. 1981. Corrections and additions to taxonomists' glossary of mosquito anatomy. Mosq. Syst., 13: 201-217.

Harbach, R. E. and Peyton, E. L. 1993. Morphology and evolution of the larval maxilla and its importance in the classification of the Sabethini (Diptera: Culicidae). Mosq. Syst., 25: 1-16.

Miyagi, I. and Toma, T. 2007. A new mosquito of the genus Topomyia (Diptera, Culicidae) from a Nepenthes pitcher plant in Bario highland of Sarawak, Malaysia. Med. Entomol. Zool., 58: 167-174.

Miyagi, I., Toma, T. and Okazawa, T. 2006. Redescription of Topomyia argenteoventralis Leicescter, 1908 (Diptera: Culicidae) from Malaysia. Med. Entomol. Zool., 57: 347-354. 